\title{
OPEN The role of dislocation-solute interactions on the creep behaviour of binary Mg-RE alloys
}

\author{
Jing $\mathrm{Li}^{1}$, Jialin $\mathrm{Wu}^{1}{ }^{1}, \mathrm{Li} \mathrm{Jin}^{1 凶}$, Mert Celikin ${ }^{2}$, Fenghua Wang ${ }^{1}$, Shuai Dong ${ }^{1}$ \& Jie Dong ${ }^{1}$
}

The effect of dislocation-RE atoms interactions on the creep behaviour has been studied via creep testing and HAADF-STEM analysis of two extruded alloys; Mg-0.5Ce and Mg-2Gd (wt\%). Almost no $\mathrm{Ce}$ atoms are detected in the Mg matrix due to the low solid solubility and faster diffusion rate in as-extruded condition. However, Gd solute segregations are observed along dislocations and hexagonal dislocation patterns. Such segregations can not only pin the dislocation motion and enhance the creep strengthening via dislocation patterns, but also lead to dynamic precipitation. Thus, combing with the stress exponent values, the transition of creep mechanism between $\mathrm{Mg}-0.5 \mathrm{Ce}$ alloys and $\mathrm{Mg}-2 \mathrm{Gd}$ alloys has been found and dislocation-Gd atoms interactions are determined to be the main factor for superior creep resistance of $\mathrm{Mg}-2 \mathrm{Gd}$ alloys.

Rare earth (RE) elements are intentionally added to pure Mg to modify the mechanical properties ${ }^{1-4}$. If the RE concentration is lower than its solid solubility in pure $\mathrm{Mg}$, the strengthening effect ordinarily comes from the solid solution strengthening, which is conventionally attributed to the elastic interactions between dislocations and local lattice strain caused by RE atoms ${ }^{5}$. However, at high temperatures, the large differences in the atomic radii between $\mathrm{RE}$ and $\mathrm{Mg}$ atoms can also lead to solute segregation around dislocation cores. Such solute clusters or orderings can exert a drag force on the gliding dislocations, slow down the dislocation motion and thus tailor the macroscopic properties of $\mathrm{Mg}$ alloys ${ }^{6-9}$. One typical example regarding such interactions is the Portevin-Le Chatelier (PLC) effect ${ }^{10}$. Within particular temperature and strain rate ranges, mobile dislocations can be continuously pinned and unpinned by RE solute atmospheres and ultimately exhibiting serrations in the flow curve. Zhu et al. ${ }^{11}$ have reported that the PLC effect can not only lead to the negative sensitivity of stress to strain rate but also a plateau in the temperature dependent yield and ultimate strength. Moreover, dislocation substructures can serve as templates for the segregation of RE atoms at high temperatures ${ }^{12}$. Li et al. ${ }^{13}$ discovered the hexagonal patterning Gd nanofibers in extruded $\mathrm{Mg}-\mathrm{Gd}$ binary alloys and illustrated that these nano structures can potentially modify the mechanical performance by tunning the work hardening behaviour. Therefore, it is of importance to pay attention to the interactions between dislocations and RE atoms as well as their effect on the macroscopic properties, particularly for the plastic deformation at high temperatures.

Limited creep resistance has been regarded as one of the principal hurdles which are restricting the widespread applications of $\mathrm{Mg}_{\text {alloys }}{ }^{14,15}$. One critical strategy enhancing the creep performance is to alloy $\mathrm{Mg}$ with RE elements. To date, solid solution and dynamic precipitation strengthening, if possible, are the two main hardening mechanisms which are responsible for the appealing creep properties ${ }^{16-18}$. Mo et al. ${ }^{19}$ also tried to relate the superior high temperature behavior of binary $\mathrm{Mg}$ - $\mathrm{RE}$ solid solutions to the short-range order strengthening effect. However, the nature of interactions between dislocations and RE solutes is still ambiguous despite the studies available that have successfully used modelling to shed light into the effects of RE elements ${ }^{20,21}$. There is a lack of experimental data on dislocation-RE solute interactions during creep as it is challenging to isolate the effect of solutes only where grain size and precipitates are important factors as well. In this study, we investigated the dislocation-solute interactions in two binary $\mathrm{Mg}-0.5 \mathrm{Ce}$ and $\mathrm{Mg}-2 \mathrm{Gd}$ (wt\%) alloys crept at $200{ }^{\circ} \mathrm{C}$, using high-angle annular dark-field scanning transmission electron microscopy (HAADF-STEM) technique to obtain atomic scale information. Ce and Gd elements are chosen here because they are the most common REs and have different solid solubility limits in pure $\mathrm{Mg}$, i.e., $0.74 \mathrm{wt} \%$ and $3.82 \mathrm{wt} \%$, respectively, at $200^{\circ} \mathrm{C}^{20}$. The results might provide valuable information for better understanding of strengthening mechanism for solid solution $\mathrm{Mg}-\mathrm{RE}$ alloys with enhanced creep resistance and shed light for creep resistant $\mathrm{Mg}$ alloy design.

\footnotetext{
${ }^{1}$ National Engineering Research Center of Light Alloy Net Forming and State Key Laboratory of Metal Matrix Composite, School of Materials Science and Engineering, Shanghai Jiao Tong University, Shanghai 200240, China. ${ }^{2}$-Form Advanced Manufacturing Research Centre, School of Mechanical and Materials Engineering, University College Dublin, Belfield, Dublin 4, Ireland. ${ }^{\varpi}$ email: j_jinli@sjtu.edu.cn
} 


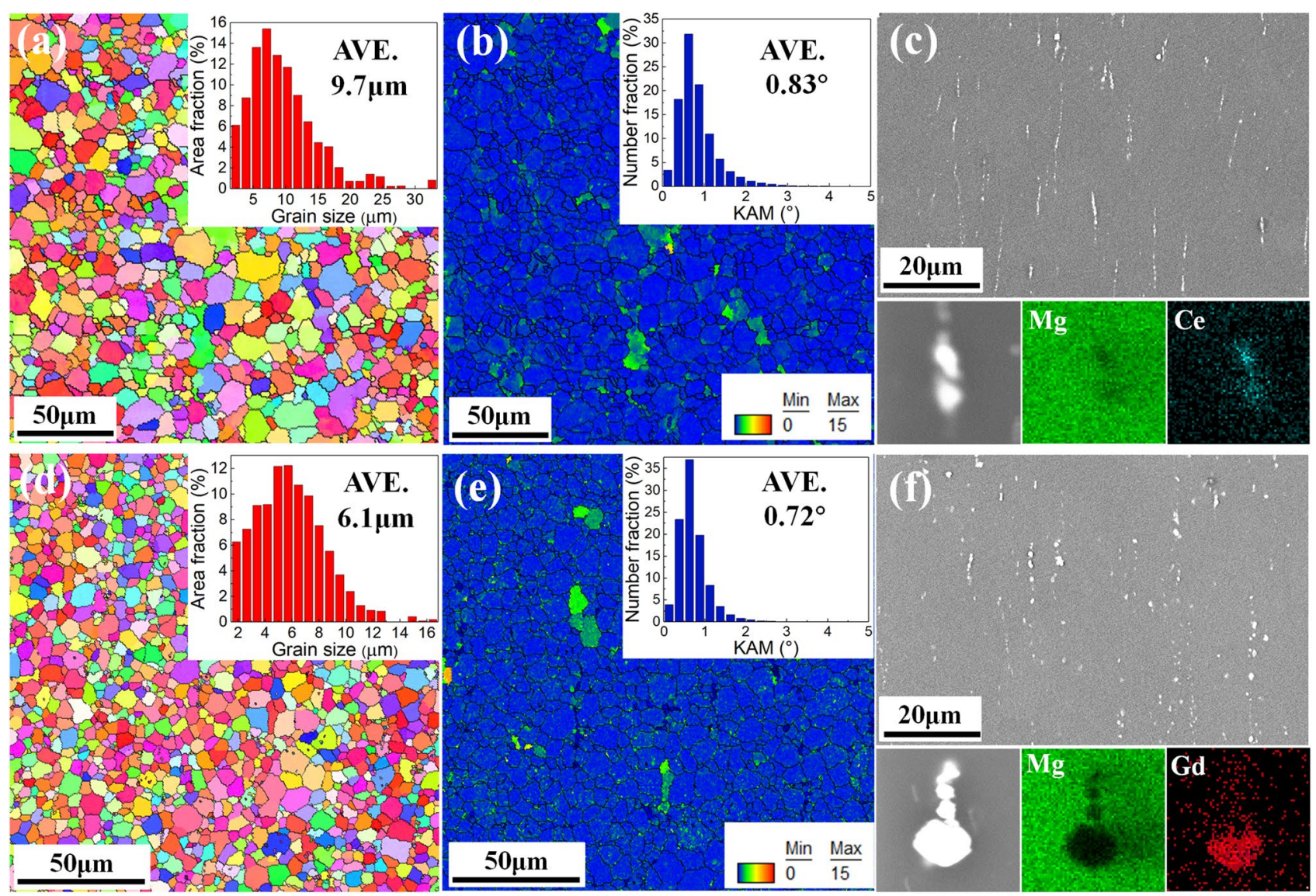

Figure 1. Microstructure of extruded $\mathrm{Mg}-0.5 \mathrm{Ce}$ (the first row) and $\mathrm{Mg}-2 \mathrm{Gd}$ alloys (the second row) before creep tests: (a,d) EBSD orientation maps, (b,e) KAM images, (c,f) SEM images and EDS analysis.

\section{Methods}

$\mathrm{Mg}-0.5 \mathrm{Ce}$ and $\mathrm{Mg}-2 \mathrm{Gd}$ alloys ingots were solution treated at $520^{\circ} \mathrm{C}$ for $8 \mathrm{~h}$, followed by quenching into water, and then extruded at $350^{\circ} \mathrm{C}$. Dog-bone tensile samples (with a gage length of $15 \mathrm{~mm}$ and cross-sectional dimension of $3.5 \times 2.2 \mathrm{~mm}^{2}$ ) and flat tensile creep samples (with a gage length of $25 \mathrm{~mm}$ and cross-sectional dimension of $6 \times 2 \mathrm{~mm}^{2}$ ), in accordance with the ASTM-E21 and ASTM-E139 standards, respectively, were machined out of the two as-extruded bars along the extrusion direction (ED). High temperature tensile tests were performed at $150-250{ }^{\circ} \mathrm{C}$ with a strain rate of $0.001 \mathrm{~s}^{-1}$. Tensile creep tests were carried out at temperature of $200{ }^{\circ} \mathrm{C}$ and applied stress of 30-50 MPa for Mg-0.5Ce alloys and 50-90 MPa for Mg-2Gd alloys, respectively. Prior to SEM, EDS and EBSD examinations, the sample surfaces were prepared by $\mathrm{SiC}$ paper, $6 \mu \mathrm{m}, 3 \mu \mathrm{m}, 1 \mu \mathrm{m}$ diamond suspension and OPS suspension. The step size used in EBSD tests was $0.5 \mu \mathrm{m}$. Data obtained from the EBSD tests were analyzed using TSL OIM software. TEM observation was carried out using JEM $2100 \mathrm{~F}$ TEM at $200 \mathrm{kV}$ and HAADF-STEM mode of JEOL-ARM200F microscope with a probe-forming lens corrector. All TEM samples were water quenched immediately after creep tests and then prepared by dimple grinding and ion-milling using a Gatan precision ion polishing system (PIPS II MODEL 695).

\section{Results and discussion}

Figure 1 shows the initial microstructure of the as-extruded $\mathrm{Mg}-0.5 \mathrm{Ce}$ and $\mathrm{Mg}-2 \mathrm{Gd}$ alloys. As can be seen, the two alloys exhibit similar average grain size, i.e., $9.7 \mu \mathrm{m}$ for $\mathrm{Mg}-0.5 \mathrm{Ce}$ and $6.1 \mu \mathrm{m}$ for $\mathrm{Mg}-2 \mathrm{Gd}$ alloys, respectively. (Fig. 1a,d). The kernel average misorientation (KAM) plot in Fig. 1b,e show that both $\mathrm{Mg}-0.5 \mathrm{Ce}$ and $\mathrm{Mg}-2 \mathrm{Gd}$ alloys have low residual strain. KAM value has a relationship with geometry necessary dislocations (GNDs) and hence can refer to the residual strain ${ }^{21}$. Figure 1c,f show the SEM and EDS results for Mg-0.5Ce and $\mathrm{Mg}-2 \mathrm{Gd}$ alloys. During extrusion at high temperature, RE-based dynamic precipitation occurred in both alloys since those secondary precipitations are not found in the alloys after solution treatment (Fig. S1) and are parallel to the ED. Dynamic precipitates formed are most probably $\mathrm{Mg}_{12} \mathrm{Ce}(\mathrm{Mg}-0.5 \mathrm{Ce})$ and $\mathrm{Mg}_{5} \mathrm{Gd}(\mathrm{Mg}-2 \mathrm{Gd})$ as they are the most stable secondary phases observed in previous studies ${ }^{22,23}$.

Figure 2a,e show the tensile curves of the two alloys at the temperatures ranging from 150 to $250^{\circ} \mathrm{C}$. Smooth flow curves are observed for the $\mathrm{Mg}-0.5 \mathrm{Ce}$ alloys. However, the $\mathrm{Mg}-2 \mathrm{Gd}$ alloys exhibit serrated flow at the temperatures of $150^{\circ} \mathrm{C}$ and $200^{\circ} \mathrm{C}$ and the serrations disappear at $250^{\circ} \mathrm{C}$. Extensive studies have illustrated that those serrated curves at high temperature are known as PLC effect, caused by the drag force of diffusion solute atoms which pin the dislocations temporarily and then raise the stress to reactive them ${ }^{10,11}$. For the purpose of investigating the interactions between dislocations and solute atoms during creep process, the temperature 
(a)
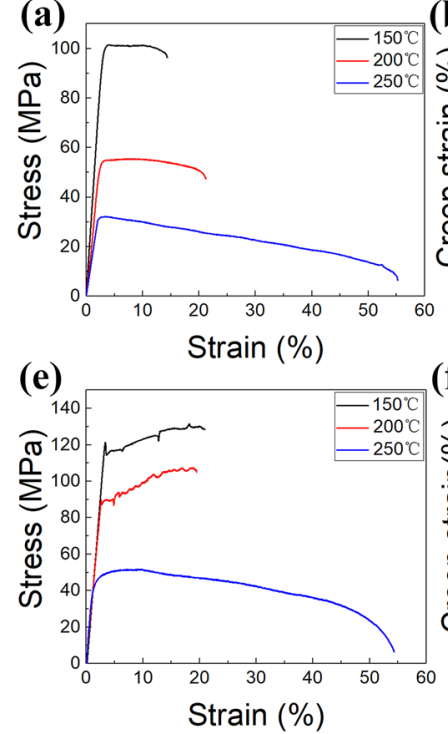

(b)

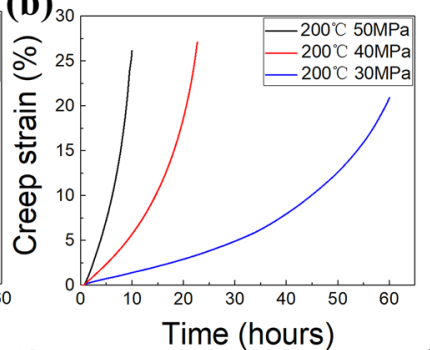

(f)

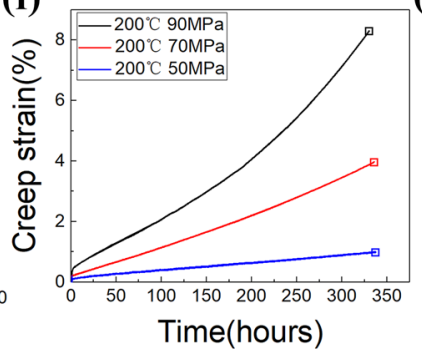

(c)

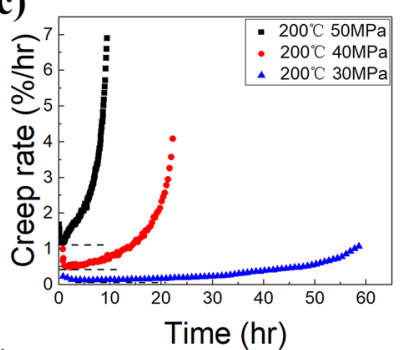

$(\mathbf{g})_{0}$

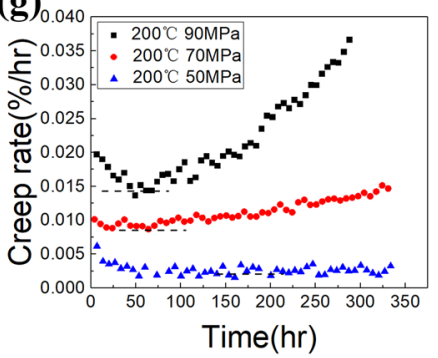

(d)

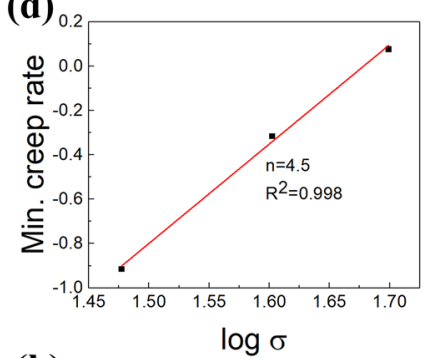

(h)

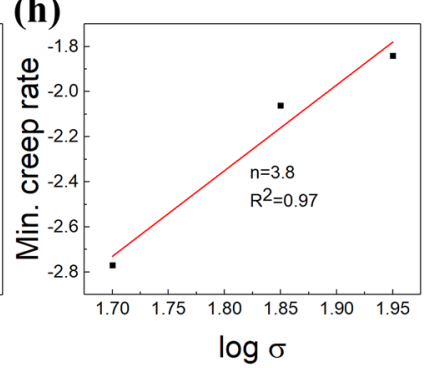

Figure 2. Mechanical behaviours of $\mathrm{Mg}-0.5 \mathrm{Ce}$ (the first row) and $\mathrm{Mg}-2 \mathrm{Gd}$ alloys (the second row) at high temperature: $(\mathbf{a}, \mathbf{e})$ tension curves at the temperature ranging from 150 to $250{ }^{\circ} \mathrm{C},(\mathbf{b}, \mathbf{f})$ tension creep curves at $200^{\circ} \mathrm{C}$ and various applied stress, in which squares mark the point that testing is terminated artificially, $(\mathbf{c}, \mathbf{g})$ creep rate vs. time images, $(\mathbf{d}, \mathbf{h}) \log$ steady state strain rate plotted as a function of log stress.

\begin{tabular}{|c|c|c|c|c|c|}
\hline Samples & Temperature $\left({ }^{\circ} \mathrm{C}\right)$ & Applied stress (MPa) & $\begin{array}{l}\text { Ratio of the applied } \\
\text { stress to the yield stress } \\
\text { at } 200^{\circ} \mathrm{C}\end{array}$ & $\begin{array}{l}\text { Minimum creep rate } \\
(\% / \mathbf{h})\end{array}$ & Creep life (h) \\
\hline \multirow{3}{*}{$\mathrm{Mg}-0.5 \mathrm{Ce}$ alloys } & \multirow{3}{*}{200} & 30 & 0.55 & 0.14 & 60 \\
\hline & & 40 & 0.73 & 0.51 & 23 \\
\hline & & 50 & 0.91 & 1.20 & 10 \\
\hline \multirow{3}{*}{ Mg-2Gd alloys } & \multirow{3}{*}{200} & 50 & 0.54 & 0.0025 & $>330$ \\
\hline & & 70 & 0.76 & 0.0091 & $>330$ \\
\hline & & 90 & 0.98 & 0.0144 & $>330$ \\
\hline
\end{tabular}

Table 1. Summary of the creep properties of $\mathrm{Mg}-0.5 \mathrm{Ce}$ and $\mathrm{Mg}-2 \mathrm{Gd}$ alloys.

of $200{ }^{\circ} \mathrm{C}$ is chosen to carry out the creep tests since at this temperature serrated flow curve is detected for the $\mathrm{Mg}-2 \mathrm{Gd}$ alloys but not for the $\mathrm{Mg}-0.5 \mathrm{Ce}$ alloys. Additionally, the yield stress for the two alloys at $200{ }^{\circ} \mathrm{C}$ is different, i.e., $55 \mathrm{MPa}$ for $\mathrm{Mg}-0.5 \mathrm{Ce}$ alloys and $92 \mathrm{MPa}$ for $\mathrm{Mg}-2 \mathrm{Gd}$ alloys. For comparison, the applied stress which has similar ratio to the yield stress for the two alloys at $200^{\circ} \mathrm{C}$ is selected for creep tests, which is listed in Table.1.

The creep responses of the two investigated alloys are displayed in Fig. 2b,f by strain vs. time plots. A remarkable improvement in creep resistance is found for the $\mathrm{Mg}-2 \mathrm{Gd}$ alloys in comparison to the $\mathrm{Mg}-0.5 \mathrm{Ce}$ alloys. For example, at the temperature of $200{ }^{\circ} \mathrm{C}$ and the ratio of applied stress to yield stress of $\sim 0.55$, the $\mathrm{Mg}-0.5 \mathrm{Ce}$ alloys failed at $60 \mathrm{~h}$ with a strain of $\sim 21 \%$ but the $\mathrm{Mg}-2 \mathrm{Gd}$ alloys remain intact after lasting $350 \mathrm{~h}$ showing a strain of $\sim 1 \%$. It can also be seen from Fig. $2 \mathrm{c}, \mathrm{g}$ that the minimum creep rates of $\mathrm{Mg}-2 \mathrm{Gd}$ alloys are almost two orders of magnitude lower than that of $\mathrm{Mg}-0.5 \mathrm{Ce}$ alloys. Figure $2 \mathrm{~d}$,h show the log minimum creep rate vs. $\log$ stress for $\mathrm{Mg}-0.5 \mathrm{Ce}$ and $\mathrm{Mg}-2 \mathrm{Gd}$ alloys. As can be seen, the stress exponent decreases from 4.5 for the $\mathrm{Mg}-0.5 \mathrm{Ce}$ alloys to 3.8 for the $\mathrm{Mg}-2 \mathrm{Gd}$ alloys. It has been widely accepted that dislocation gliding and climbing is most likely the dominant mechanism when the stress exponent is in the range of 4-7 but solute drag dislocation gliding takes the controlling role as the stress exponent reduces to $3^{24-26}$. The values of all critical creep properties are summarized in Table.1.

To further probe the creep mechanisms, in-depth dislocation analysis is conducted in the $\mathrm{Mg}-0.5 \mathrm{Ce}$ and $\mathrm{Mg}-2 \mathrm{Gd}$ alloys after terminating the creep tests near their minimum creep rates, i.e., after $\sim 3 \mathrm{~h}$ at the applied stress of $40 \mathrm{MPa}$ for $\mathrm{Mg}-0.5 \mathrm{Ce}$ alloys and after $\sim 60 \mathrm{~h}$ at $70 \mathrm{MPa}$ for $\mathrm{Mg}-2 \mathrm{Gd}$ alloys, respectively. Figure 3a,b show the TEM images taken under the two beam conditions for the $\mathrm{Mg}-0.5 \mathrm{Ce}$ alloys. The dislocations are identified as $<\mathrm{a}>$ type dislocations based on the $\mathrm{g} \cdot \mathrm{b}$ analysis that they are visible under $g=\left\{\begin{array}{lll}01 & \overline{1} & 0\end{array}\right\}$ and invisible under $g=\{0002\}$. Moreover, most of the dislocation lines lying along the basal plane trace are basal $<\mathrm{a}>$ dislocations and several dislocation segments extending out of the basal plane suggest that cross slip occurs. Additionally, a few short $<$ a $>$ dislocations piling up in arrays and parallel to each other, as marked by the yellow squares, are detected in the $\mathrm{Mg}-0.5 \mathrm{Ce}$ alloys, which are probably resulted from the dislocation climbing. Thus, dislocation 

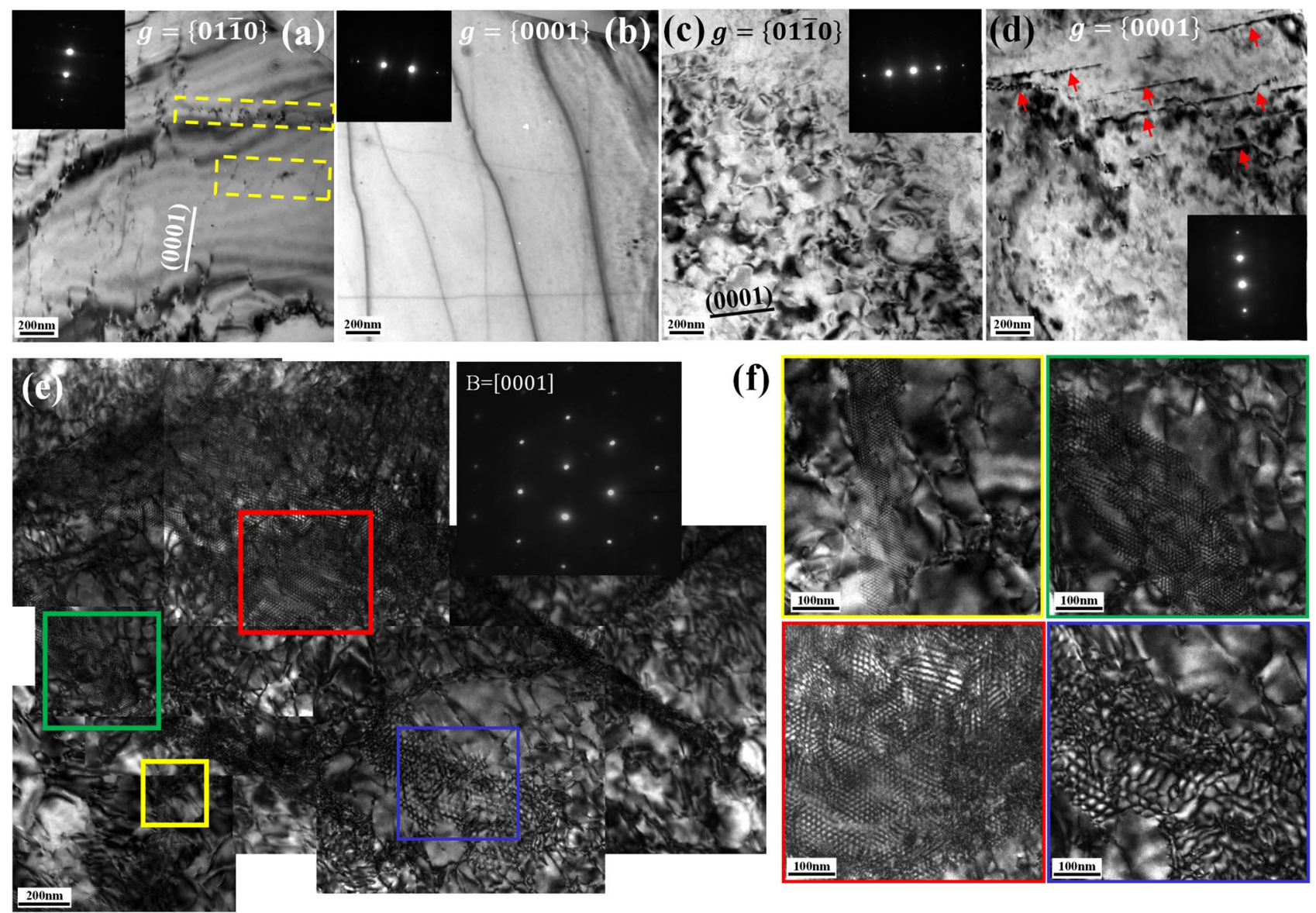

Figure 3. TEM images taken near the minimum creep rates, i.e., after $\sim 3 \mathrm{~h}$ at the applied stress of $40 \mathrm{MPa}$ for Mg-0.5Ce alloys and $60 \mathrm{~h}$ at $70 \mathrm{MPa}$ for Mg-2Gd alloys: (a,b) two beam conditions for the Mg-0.5Ce alloys, where dislocation climbing is marked by the yellow squares, $(\mathbf{c}, \mathbf{d})$ two beam conditions for $\mathrm{Mg}-2 \mathrm{Gd}$ alloys, in which the $<\mathrm{c}>$ dislocations are marked by the red arrows, (e) the hexagonal dislocation patterns observed along the [0001] axis in the Mg-2Gd alloys, (f) corresponding enlarged images marked by the squares in (e).

gliding and climbing are the main creep mechanisms of $\mathrm{Mg}-0.5 \mathrm{Ce}$ alloys, agreeing well with the determined stress exponent.

TEM images taken from the Mg-2Gd alloys are shown in Fig. 3c,d. In addition to basal $<\mathrm{a}>$ dislocations, some $<\mathrm{c}>$ type dislocations, as marked by the red arrows, are also recognized in the $\mathrm{Mg}-2 \mathrm{Gd}$ alloys as they are visible under $g=\{0002\}$ and invisible under $g=\left\{\begin{array}{lll}01 & \overline{1} & 0\end{array}\right\} .<\mathrm{c}>$ dislocations can come from two sources, either the activated $<c>$ slips or the dissociation of $\left\langle\mathrm{c}+\mathrm{a}>\right.$ dislocations $\mathrm{s}^{27,28}$. When $<\mathrm{c}+\mathrm{a}>$ dislocations dissociate into $<\mathrm{a}>$ and $<\mathrm{c}>$ dislocations, basal $<\mathrm{a}>$ dislocations can glide easily to annihilate with the opposite signed $<\mathrm{a}>$ dislocations and hence $<c>$ dislocations are left ${ }^{29}$. In addition, from Fig. 3c, higher percentage of cross slip is observed in the $\mathrm{Mg}-2 \mathrm{Gd}$ alloys in comparison to the $\mathrm{Mg}-0.5 \mathrm{Ce}$ alloys as most of the $<\mathrm{a}>$ dislocations found in the $\mathrm{Mg}-2 \mathrm{Gd}$ alloys are lying out of the basal plane. This may be partly due to the higher applied stress, but the solute drag force may also play a role. Since the drag force exerted by the solid atmosphere affects the mobility of basal dislocations, dislocations may cross slip to non-basal planes under the thermal activation to relieve the stress concentration. However, the interactions between dislocations and RE atoms need to be further confirmed at atom scale, which will be addressed later in this work.

Moreover, viewed from the [0001] axis as shown in Fig. 3e, hexagonal dislocation patterns, which extend a few microns in size, are detected in the secondary creep stage of $\mathrm{Mg}-2 \mathrm{Gd}$ alloys. From the corresponding enlarged images in Fig. 3f, we can see that such dislocation patterns exhibit different inter-spacings ranging from 4 to $40 \mathrm{~nm}$. Hexagonal dislocation patterns have also been found in pure $\mathrm{Mg}$ after compression at $400{ }^{\circ} \mathrm{C}$ and are related to the self-assemble of a set of parallel $<\mathrm{c}>$-screw dislocation dipole ${ }^{29} .<\mathrm{c}>$ type dislocations are observed in the $\mathrm{Mg}-2 \mathrm{Gd}$ alloy by using two beam conditions, as shown in Fig. 3d. No such dislocation patterns found in the $\mathrm{Mg}-0.5 \mathrm{Ce}$ alloys are also understandable since there are few $\langle\mathrm{c}\rangle$ dislocations observed. Moreover, we should note that such dislocation patterns are not observed in the first and third creep stages of $\mathrm{Mg}-2 \mathrm{Gd}$ alloys as well. In this sense, a strong forest strengthening exerted by such dislocation patterns would be expected. This can be related to the unique orientation of those hexagonal patterned $\langle\mathrm{c}\rangle$ dislocations, which is lying along the [0001] axis, and hence have a high possibility of inhibiting the easy-gliding basal slip. In addition, the segregation of 


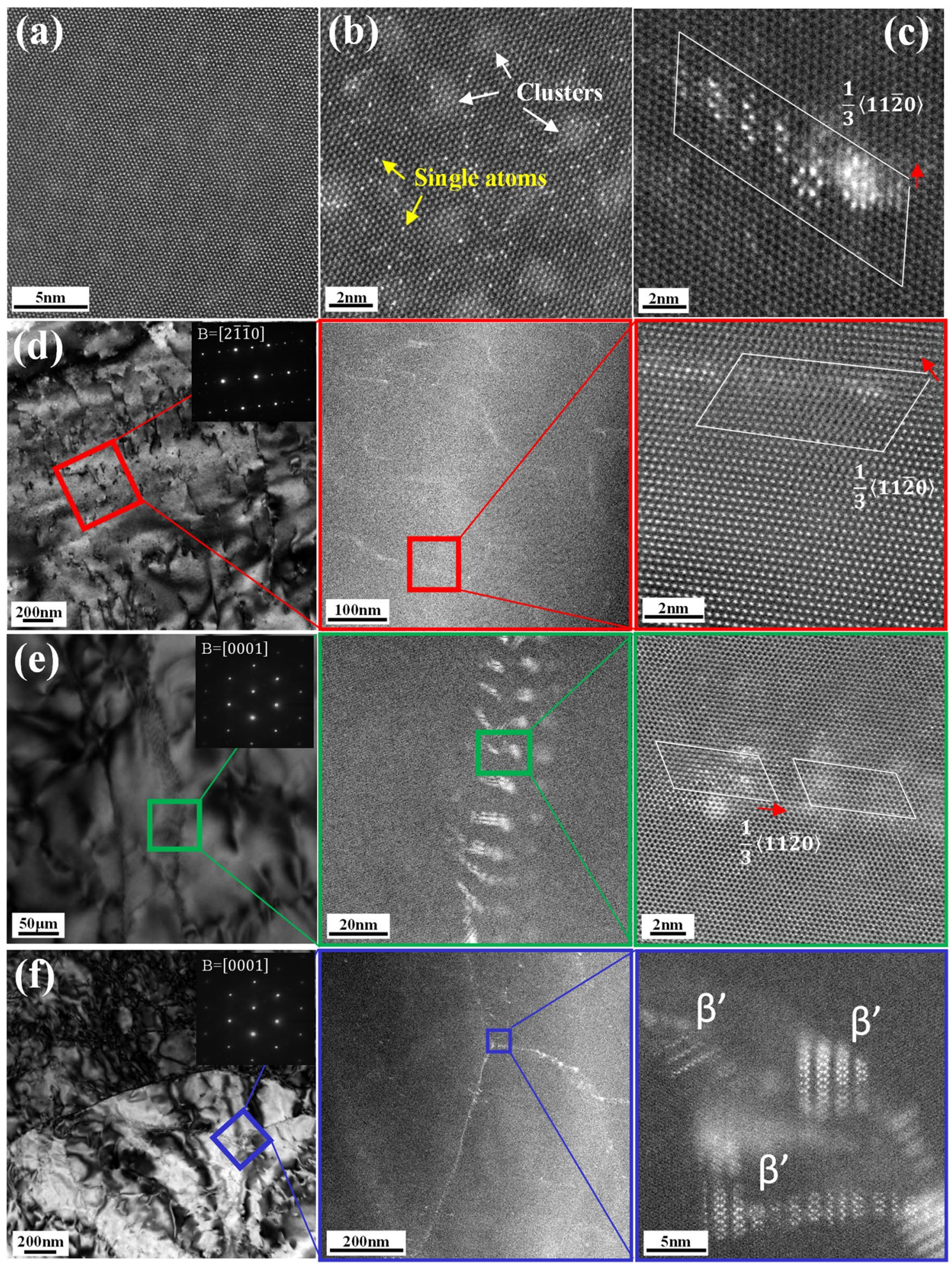

Figure 4. HAADF-STEM images taken near the minimum creep rates, i.e., after $\sim \mathrm{h}$ at the applied stress of $40 \mathrm{MPa}$ for $\mathrm{Mg}-0.5 \mathrm{Ce}$ alloys and $\sim 60 \mathrm{~h}$ at $70 \mathrm{MPa}$ for Mg-2Gd alloys: (a) Mg-0.5Ce alloys recorded along the $\left[\begin{array}{llll}2 & 1 & 1 & 0\end{array}\right]$ zone axis, (b-f) Mg-2Gd alloys.

Gd clusters which can form the Gd-nano fibers would also possibly play a role in, as the Gd segregations were previously reported in the extruded $\mathrm{Mg}-1 \mathrm{Gd}$ alloys ${ }^{13}$.

Due to the large difference between the atomic numbers of the constituent elements (Mg: 12, Ce: 58, Gd: 64), it is easy to detect the heavy $\mathrm{Ce}$ and $\mathrm{Gd}$ atoms in the Mg matrix by using HAADF-STEM ${ }^{30,31}$. The investigated samples taken from the $\mathrm{Mg}-0.5 \mathrm{Ce}$ and $\mathrm{Mg}-2 \mathrm{Gd}$ alloys are under the same creep conditions as those of TEM samples, respectively. Figure 4a shows the atomic-resolution HAADF-STEM image of the Mg-0.5Ce alloys 
recorded along the $\left[\begin{array}{llll}2 & 1 & 1 & 0\end{array}\right]$ zone axis. Surprisingly, no bright Ce atoms are detected in the $\mathrm{Mg}$ matrix. Another grain has also been investigated along the [0001] axis, still no Ce atoms are observed (Fig. S2). However, Gd atoms can be seen in the $\mathrm{Mg}$ matrix of the $\mathrm{Mg}-2 \mathrm{Gd}$ alloys, either as single atoms or as clusters (Fig. $4 \mathrm{~b}$ ). The lack of Ce atoms is probably due to the lower Ce content $(0.5 \mathrm{wt} \%)$ and faster diffusion rates of Ce solute than $\mathrm{Gd}^{32}$. Faster diffusion rate allows the formation and growth of Ce-based dynamic precipitates during extrusion at $350{ }^{\circ} \mathrm{C}$ leading to the depletion of $\mathrm{Ce}$ atoms in the $\mathrm{Mg}$ matrix prior to the creep testing. Hence, it can be stated that $\mathrm{Mg}-0.5 \mathrm{Ce}$ alloys would show similar creep behaviour with pure $\mathrm{Mg}$ when the deformation is controlled via dislocation-based creep processes. Crossland and Jones ${ }^{33}$ conducted creep tests on pure $\mathrm{Mg}$ and found that the stress exponent $\mathrm{n}$ was 4.4 at the temperature of $200^{\circ} \mathrm{C}$ and in the stress range of $17-31 \mathrm{MPa}$. Given that the yield stress of pure $\mathrm{Mg}$ at $200^{\circ} \mathrm{C}$ is $25-32 \mathrm{MPa}^{34,35}$, represents similar ratios between stresses used during creep testing and the high temperature yield strength with the ones used in present study for $\mathrm{Mg}-0.5 \mathrm{Ce}$ and $\mathrm{Mg}-2 \mathrm{Gd}$ alloys. Vagarali and Langdon ${ }^{36}$ also reported a stress exponent of 5.5 under similar creep testing conditions. Thus, dislocation gliding and climbing are also suggested as the main creep mechanisms for pure $\mathrm{Mg}$, similar with that of $\mathrm{Mg}-0.5 \mathrm{Ce}$ alloys.

Enlarged image in Fig. 4c shows a dislocation with the Burger vector of $\frac{1}{3}\langle 11 \overline{2} 0\rangle$ in the Mg-2Gd alloys. Bright contrast at the dislocation core indicates the G.P. zone consisting of Gd atoms, which are arranged as hexagonal and zig-zag chains. Such interactions between dislocations and Gd atoms can also be observed along the [ $\left[\begin{array}{llll}2 & 1 & 1 & 0\end{array}\right]$ axis. As shown in Fig. 4d, a continuous bright contrast is seen along the dislocations. Detailed Burger circuit analysis further identifies the dislocations as <a $>$ type. As illustrated extensively, the strain field associated with dislocations should be the reason for the segregation of $\mathrm{Gd}$ atoms $\mathrm{s}^{8,37,38}$. Under the consideration of reducing the elastic strain of individual solute atoms, the observation of G.P. zones rather than Gd clusters can also be understood $^{39}$. Figure $4 \mathrm{e}$ shows the segregation of $\mathrm{Gd}$ atoms in the hexagonal dislocation patterns, as confirmed by the bright intensity in the corresponding HAADF-STEM images. Burger's loop analysis was used to recognize the dislocation type, which shows such dislocation patterns not only consist of $<$ a $>$ dislocations but also the dislocations with closed Burgers circuits. Combining experimental results and model calculation, Liu et al..$^{29}$ illustrated those dislocations showing no edge components are $<\mathrm{c}>$-screw dislocations. Li et al. ${ }^{13}$ further observed such Gd segregation along the $\left[\begin{array}{lll}1 & 2 & 0\end{array}\right]$ axis and found that Gd segregation templated to the dislocation patterns can finally lead to the formation of the Gd nano-fibers with the $<\mathrm{c}>$ rod shape. Based on above experimental results, the interactions between dislocations and Gd atoms are confirmed in the Mg-2Gd alloys, either in the way of segregating along the dislocations or into the hexagonal dislocation patterns. The stress exponent is valid for the $\mathrm{Mg}-2 \mathrm{Gd}$ alloys and solute drag gliding is verified to be the main creep mechanism.

Therefore, it is found that the creep mechanism changes from dislocation gliding and climbing for the $\mathrm{Mg}-0.5 \mathrm{Ce}$ alloys to solute drag dislocation gliding for the $\mathrm{Mg}-2 \mathrm{Gd}$ alloys even under the same creep temperature and the ratio of the applied stress to yield stress for the two alloys are similar. In this case, apart from the solid solute strengthening offered by higher concentration of $\mathrm{Gd}$ atoms, dislocation-Gd atoms interactions also play a critical role in the superior creep resistance of the $\mathrm{Mg}-2 \mathrm{Gd}$ alloys. Firstly, Gd segregation would exert a strong pinning effect on the dislocation motion and reduce the creep rate dramatically. Secondly, the strengthening effect achieved from the hexagonal dislocation patterns can be further enhanced by Gd segregation. On one side, such segregation can reduce the dislocation core energy and then improve the dislocation patterns' stability ${ }^{40}$. On the other side, the formed Gd nano fibers can act as effective obstacles for the easy-gliding basal dislocations since they are parallel to the [0001] axis $^{13}$. Moreover, such interactions would lead to dynamic precipitation. As seen in Fig. 4f, $\beta^{\prime}$ phases are formed along the low angle grain boundary. In this case, dynamic precipitates also offer a certain strengthening effect for the higher creep resistance shown in the $\mathrm{Mg}-2 \mathrm{Gd}$ alloys.

In summary, after comparing the creep behavior of extruded $\mathrm{Mg}-0.5 \mathrm{Ce}$ and $\mathrm{Mg}-2 \mathrm{Gd}$ alloys under the temperature of $200^{\circ} \mathrm{C}$ and the similar ratio of the applied stress to the yield stress, a transition of the creep mechanism from dislocation climb for the $\mathrm{Mg}-0.5 \mathrm{Ce}$ alloys to solute drag dislocation glide for the $\mathrm{Mg}-2 \mathrm{Gd}$ alloys has been verified. Low solid solubility and faster diffusion rate of Ce lead to almost no Ce atoms left in the $\mathrm{Mg}$ matrix upon high temperature extrusion. However, the interactions between dislocations and Gd atoms are detected in the as-extruded Mg-2Gd alloys. Such interactions can not only exert a drag effect on the dislocation motion and enhance the strengthening effect offered by the hexagonal dislocation patterns, but also lead to the formation of dynamic precipitation. In this case, dislocation-Gd atoms interactions are crucial for the high creep resistance of the $\mathrm{Mg}-2 \mathrm{Gd}$ alloys.

Received: 6 December 2020; Accepted: 15 January 2021

Published online: 03 February 2021

\section{References}

1. Abaspour, S. \& Cáceres, C. H. Thermodynamics-based selection and design of creep-resistant cast Mg alloys. Metall. Mater. Trans. A 46(12), 5972-5988 (2015).

2. Mo, N. et al. Current development of creep-resistant magnesium cast alloys: A review. Mater. Des. 155, 422-442 (2018).

3. Pekguleryuz, M. \& Celikin, M. Creep resistance in magnesium alloys. Int. Mater. Rev. 55(4), 197-217 (2013).

4. Yuan, L., Shi, W., Jiang, W., Zhao, Z. \& Shan, D. Effect of heat treatment on elevated temperature tensile and creep properties of the extruded Mg-6Gd-4Y-Nd-0.7Zr alloy. Mater. Sci. Eng. A 658, 339-347 (2016).

5. Suzuki, M., Sato, H., Maruyama, K. \& Oikawa, H. Creep behavior and deformation microstructures of Mg-Y alloys at $550 \mathrm{~K}$. Mater. Sci. Eng. A 252(2), 248-255 (1998).

6. Hadorn, J. P. et al. Solute clustering and grain boundary segregation in extruded dilute Mg-Gd alloys. Scr. Mater. 93, 28-31 (2014).

7. Hu, W. W., Yang, Z. Q. \& Ye, H. Q. Cottrell atmospheres along dislocations in long-period stacking ordered phases in a Mg-Zn-Y alloy. Scr. Mater. 117, 77-80 (2016). 
8. Nie, F. J., Zhu, M. Y., Liu, Z. J. \& Fang, Y. X. Periodic segregation of solute atoms in fully coherent twin boundaries. Science 20, 20 (2013).

9. Luo, X. et al. The synergy of boundary engineering and segregation strategy towards high strength and ductility Mg-3Gd alloy. J. Alloys Compd. 819, 153051 (2020).

10. Fang, X. Y., Yi, D. Q. \& Nie, J. F. The serrated flow behavior of Mg-Gd(-Mn-Sc) alloys. Metall. Mater. Trans. A 40(11), 2761-2771 (2009).

11. Zhu, S. M. \& Nie, J. F. Serrated flow and tensile properties of a Mg-Y-Nd alloy. Scr. Mater. 50(1), 51-55 (2004).

12. Liu, H. et al. Guided self-assembly of nano-precipitates into mesocrystals. Sci. Rep. 5, 1 (2015).

13. Li, Y. et al. Self-patterning Gd nano-fibers in Mg-Gd alloys. Sci. Rep. 6, 1 (2016).

14. Celikin, M., Gauvin, R. \& Pekguleryuz, M. Dynamic co-precipitation of $\alpha-\mathrm{Mn} / \mathrm{Mg} 12 \mathrm{Ce}$ in creep resistant Mg-Sr-Mn-Ce alloys. Mater. Sci. Eng. A 719, 199-205 (2018).

15. Koundinya, N. T. B. N. \& Kottada, R. S. Achieving exceptional creep resistance in rare-earth-free Mg-base alloys by engineering the shape, size and fraction of eutectic, particles and precipitates. Scr. Mater. 162, 121-126 (2019).

16. Nie, J. F., Gao, X. \& Zhu, S. M. Enhanced age hardening response and creep resistance of Mg-Gd alloys containing Zn. Scr. Mater. 53(9), 1049-1053 (2005).

17. Fang, Z. et al. Creep behaviors of hot compressed Mg-4Y-2Nd-0.2Zn-0.5Zr alloy with and without aging. Mater. Sci. Eng. A 708, 460-468 (2017).

18. Gao, L., Chen, R. S. \& Han, E. H. Effects of rare-earth elements Gd and Y on the solid solution strengthening of Mg alloys. J. Alloys Compd. 481(1-2), 379-384 (2009).

19. Mo, N. et al. Understanding solid solution strengthening at elevated temperatures in a creep-resistant Mg-Gd-Ca alloy. Acta Mater. 181, 185-199 (2019).

20. Massalski, T., Okamoto, H., Subramanian, P., \& Kacprzak, L. Binary Alloy Phase Diagrams (ASM International, Materials Park, OH, 1990), There is no corresponding record for this reference.[Google Scholar] (1991) 2983-2986.

21. Sabat, R. K., Brahme, A. P., Mishra, R. K., Inal, K. \& Suwas, S. Ductility enhancement in Mg- $0.2 \%$ Ce alloys. Acta Mater. 161, 246-257 (2018).

22. Celikin, M., Kaya, A. A., Gauvin, R. \& Pekguleryuz, M. Effects of manganese on the microstructure and dynamic precipitation in creep-resistant cast Mg-Ce-Mn alloys. Scr. Mater. 66(10), 737-740 (2012).

23. Kim, S.-H., Jung, J.-G., You, B. S. \& Park, S. H. Microstructure and texture variation with Gd addition in extruded magnesium. J. Alloys Compd. 695, 344-350 (2017).

24. Ansary, S., Mahmudi, R. \& Esfandyarpour, M. J. Creep of AZ31 Mg alloy: A comparison of impression and tensile behavior. Mater. Sci. Eng. A 556, 9-14 (2012).

25. Ouyang, S. et al. High temperature creep behavior and creep microstructure evolution of T6 state Mg-15Gd alloy. Mater. Sci. Eng. A 780, 139138 (2020).

26. Wang, H., Wang, Q. D., Boehlert, C. J., Yin, D. D. \& Yuan, J. Tensile and compressive creep behavior of extruded Mg-10Gd3Y-0.5Zr (wt\%) alloy. Mater. Charact. 99, 25-37 (2015).

27. Wu, Z. \& Curtin, W. A. The origins of high hardening and low ductility in magnesium. Nature 526(7571), 62-67 (2015).

28. Xie, K. Y. et al. Experimental observations of the mechanisms associated with the high hardening and low strain to failure of magnesium. Materialia 8, 100504 (2019).

29. Liu, Y. et al. Self-patterning screw <c> dislocations in pure Mg. Scr. Mater. 191, 86-89 (2021).

30. Xiao, L. R. et al. Solute segregation assisted nanocrystallization of a cold-rolled Mg-Ag alloy during annealing. Scr. Mater. 177, 69-73 (2020).

31. Zhou, H. et al. A new metastable precipitate phase in Mg-Gd-Y-Zr alloy. Phil. Mag. 94(21), 2403-2409 (2014).

32. Zhong, W. \& Zhao, J.-C. Measurements of diffusion coefficients of Ce, Gd and Mn in Mg. Materialia 7, 100353 (2019).

33. Crossland, I. \& Jones, R. Dislocation creep in magnesium. Metal Sci. J. 6(1), 162-166 (1972).

34. Galiyev, A., Sitdikov, O. \& Kaibyshev, R. Deformation behavior and controlling mechanisms for plastic flow of magnesium and magnesium alloy. Mater. Trans. 44(4), 426-435 (2003).

35. Chino, Y., Kobata, M., Iwasaki, H. \& Mabuchi, M. Tensile properties from room temperature to $673 \mathrm{~K}$ of Mg- 0.9 mass $\%$ Ca alloy containing lamella Mg2Ca. Mater. Trans. 43(10), 2643-2646 (2002).

36. Vagarali, S. S. \& Langdon, T. G. Deformation mechanisms in hcp metals at elevated temperatures-I. Creep behavior of magnesium. Acta Metall. 29(12), 1969-1982 (1981).

37. Kuzmina, M., Herbig, M., Ponge, D., Sandloebes, S. \& Raabe, D. Linear complexions: Confined chemical and structural states at dislocations. Science 349(6252), 1080-1083 (2015).

38. Qian, Y., Liang, Q., Tomohito, T., Rachel, T. \& David, R. Origin of dramatic oxygen solute strengthening effect in titanium. Science 347, 6222 (2015)

39. Nie, J. F., Wilson, N. C., Zhu, Y. M. \& Xu, Z. Solute clusters and GP zones in binary Mg-RE alloys. Acta Mater. 106, 260-271 (2016).

40. Lei, H., Chen, J. \& Ruterana, P. Role of c-screw dislocations on indium segregation in InGaN and InAlN alloys. Appl. Phys. Lett. 96(16), 161901 (2010).

\section{Acknowledgements}

The authors gratefully acknowledge the financial supports from the National Key Research and Development Plan (Grant no. 2016YFB0701201) and the National Natural Science Foundation of China (Grant no. 52071206).

\section{Author contributions}

J.L. was responsible for the TEM experiments and wrote the original manuscript. J.W. prepared the alloys. L.J. and M.C. were responsible for the data curation and edited the manuscript. F.W., S.D. and J.D. helped the manuscript editing. All authors discussed the results and contributed to the improvement of the manuscript text.

\section{Competing interests}

The authors declare no competing interests.

\section{Additional information}

Supplementary Information The online version contains supplementary material available at https://doi. org/10.1038/s41598-021-82517-5.

Correspondence and requests for materials should be addressed to L.J.

Reprints and permissions information is available at www.nature.com/reprints. 
Publisher's note Springer Nature remains neutral with regard to jurisdictional claims in published maps and institutional affiliations.

(c) (i) Open Access This article is licensed under a Creative Commons Attribution 4.0 International License, which permits use, sharing, adaptation, distribution and reproduction in any medium or format, as long as you give appropriate credit to the original author(s) and the source, provide a link to the Creative Commons licence, and indicate if changes were made. The images or other third party material in this article are included in the article's Creative Commons licence, unless indicated otherwise in a credit line to the material. If material is not included in the article's Creative Commons licence and your intended use is not permitted by statutory regulation or exceeds the permitted use, you will need to obtain permission directly from the copyright holder. To view a copy of this licence, visit http://creativecommons.org/licenses/by/4.0/.

(C) The Author(s) 2021 